American Journal of Applied Sciences 5 (10): 1300-1307, 2008

ISSN 1546-9239

(C) 2008 Science Publications

\title{
Utilization of Distributed Architecture Based on Internet GIS for Geomorphologic Data and Environmental Management: Case Study of Damavand Volcano Conic, Iran
}

\author{
Ebrahim Moghimi, Ali Mansourian, Mojgan Zarei Nejad and Mohammad Saber Moghimi \\ Geography College, University of Tehran, Iran \\ K.N.Toosi University of Technology, Tehran, Iran \\ Scientifics and Researches branch, Azad University, Tehran, Iran \\ Iran University of Science and Technology, Tehran, Iran
}

\begin{abstract}
Despite the great significance of geomorphologic-environmental data in different disciplines, there are sundry problems in relation to availability, accessibility and their applicability. Primarily the problems dealing with these data were investigated and then technical solutions to remove each of the above problems and how to manage geomorphologic-environmental data were suggested. The solution for availability lies in participation of various organizations in acceptance of responsibility of data production and maintenance, during their daily activities. To remove the problem of accessibility to the existing data, a distributed architecture based on Internet GIS has been proposed. To make data applicable in users' systems and also integratable with each other, formulating and observing equal standards in different stages of management of geomorphologic data is recommended. Based on the proposed solutions, Damavand Volcano conic was selected as a case study. Initial standards were drawn up. Accordingly, geomorphologic data on the case study were collected and stored in different distributed databases. A system of distributed Internet GIS was also created based on the proposed architecture. The case study indicated that the proposed solution and system are capable of eliminating the problems pertinent to management of geomorphologic data from technical perspectives.
\end{abstract}

Keywords: Internet GIS, distributed architecture, geomorphologic, management, damavand cone

\section{INTRODUCTION}

Geomorphology is the study of surface land forms and their changing ${ }^{[2]}$. Therefore, geomorphologists are concerned with the forms and processes of the earth's surface, paying heed to any form of activity transforming the form of the earth and triggering movement and replacement of materials or introducing qualitative and quantitative changes of kinetic energy and impressing $\mathrm{it}^{[14]}$. Geomorphology is counted as underpinnings of scrutiny of natural resources ${ }^{[15]}$. As understanding the natural resources cover a wide spectrum of the sciences, it is necessary for geomorphology to be linked with other branches of science such as climatology, geology, biology, ecology, pedology, hydrology and hydrogeology so as to consider all the questions in an ecosystem and in coordination with other branches of science playing its role in comprehensive plans for livestock breeding, water catchments, deforestation, forestry, environment and, generally speaking, logistics of land ${ }^{[1,13]}$. Most of geomorphologic researches are potentially applicable in most of the issues dealing with environment management, because environment management covers a wide scope of activities in applied fields of land, for example, if the aim is road policy-making, roadguarding, road-building and safety, it is preceded to the group of effective processes on roads ${ }^{[15]}$. Generally, environment management normally comprises four major stages:

- Spotting the problem,

- Systematizing the policy and planning,

- Implementing and consummating the plan and procedure,

- $\quad$ Evaluating the plan and procedure ${ }^{[15]}$

To put it differently, there are two types of focal policies: policies adopted in response to a crisis and procedures concerned with innovations of 
development ${ }^{[2]}$. As such, geomorphology and environmental studies are efficiently responsive to management of natural resources and diminishing environmental hazards, protecting the people's safety, health, welfare, not to mention locating and controlling calamity-ridden sites and exercising supervision over them $^{[15]}$. Of the most important set of information on the sciences of the earth on which geomorphology and environmental studies are constituted, one may refer to information on geology, hydrology, climatology, vegetation, soil and ... that are examined in the desired levels. With a view to the preceding, despite the importance and extensive applications of geomorphologic-environmental data, unfortunately there are numerous in connection with management of the data. Based on Feeney who has presented a general classification for problems dealing with spatial data ${ }^{[5]}$, geomorphologic-environmental data problems can be classified under three main headings in terms of data availability, accessibility and applicability.

Data availability: The concept deals with existence of data required by users. In a different word, as regards availability we seek as to whether the data required by the user exist or not. Also, the set of existing data should include characteristics such as scale (form and time), coordinate system, precision, production date and latest date of updating in favorable manner. At present, in connection with availability of geomorphologicenvironmental data required by users, can be refer to the following cases ${ }^{[6,13]}$ :

- Part of the data is available and part of it not

- Part of the data exists in several organizations, due to duplicated and parallel works

- Part of the existing data are not up to date

- Part of the existing data do not cover

- Parts of the existing data are not sufficiently precise

In many cases, a combination of the above states might occur too.

Accessibility: The term signifies accessibility to existing data for users. Some of the data may exist but users cannot have access to them or are not presented in a proper form by producer for users. In this case, although available data exists ${ }^{[6,16]}$ :

- The user is not aware of its existence

- The user has not sufficient information on how to gain access to the data
- There are no suitable mechanism and instruments for the user's easy access to the data

- Absence of the culture of exchange and policy in connection with ownership, price, patent, etc., make access to data difficult in practice (of course, the subject is not the concern of the present research)

Applicability: The concept consists of extent of conformity of available and accessible data to the needs and standards of users for their easy and speedy usage in the user's hardware and software environments. Some of the datasets may be available and accessible, but are not commensurate with the needs of users in terms of format, geometric structure, content of information, classification, definition of data, coordinate system, precision, etc. Therefore, users have to spend time and money for rehashing and preparing the data to make them applicable in their information systems (particularly GIS).

This research suggests a distributed architecture based on Internet GIS as a solution to remove the problems dealing with management of geomorphologic environmental data in Iran. Then, to justify the hypothesis, it works to implement a sample system to study the management of geomorphologicenvironmental data of Damavand with the proposed architecture.

\section{MATERIALS AND METHODS}

The studies conducted in connection with spatial data situation in $\operatorname{Iran}^{[12,16]}$ as well as different literatures on resolving spatial data problems ${ }^{[20,18,14,7,8,10,3,9,4]}$ indicate that in general there are numerous problems in relation to management of spatial data including availability, accessibility and applicability. Geomorphologic data are not exempt from this matter. To remove these problems, the present research, inspired from theories of spatial data infrastructure (SDI), distributed information management systems, Internet GIS and architecture and standards presented by $\mathrm{OGC}^{[3]}$ proposes a method and architecture for management of geomorphologic and environmental data. For better display and survey of the proposed architecture, Damavand conic zone is selected as study area. In this study area, first the database of geomorphologic of Damavand is designed and standardized and then the required data are collected, prepared and stored in distributed databases. Finally, a suitable sample system with proposed architecture is designed, implemented and connected to the mentioned database. Figure 1 shows different steps of the research. 


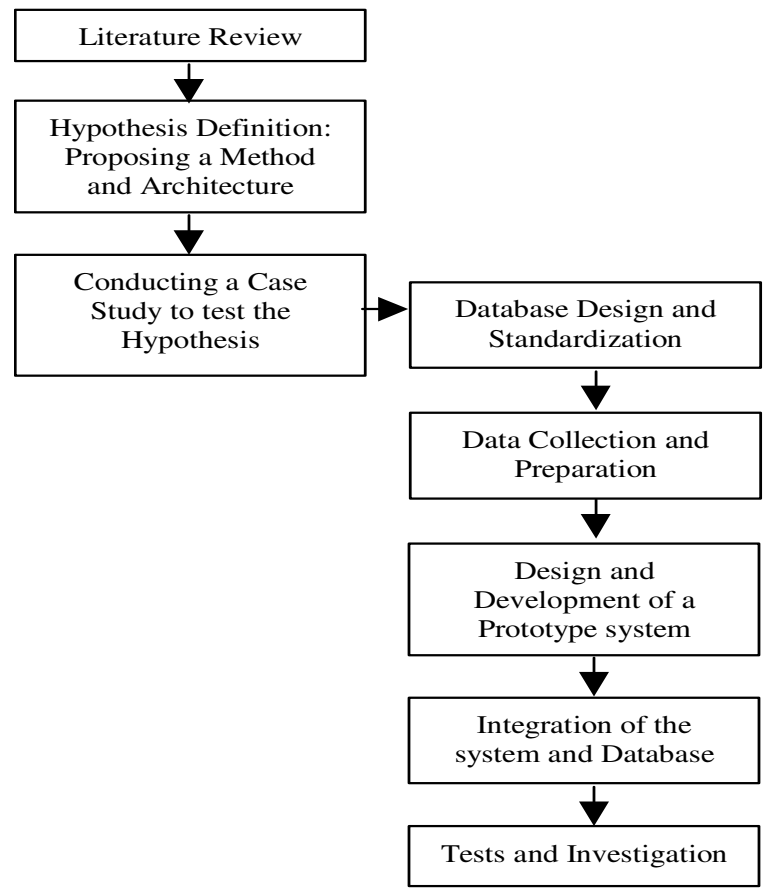

Fig. 1: Different steps of the research

Proposed architecture and the required technologies: Inspired from SDI concepts, solution to the problem dealing with availability of spatial data consists of participation and cooperation of the executive organizations in production and maintenance of geomorphologic-environmental data. If any of the executive organizations accept the responsibility of production and maintenance of part of the geomorphologic-environmental data (for example of Iran) during daily activities, commensurate with organizational missions and goals, that part of the data would always be available and up-to-date with the producer. Of course, according to description of functions and missions, two or several organizations may possibly be custodian of one type of data.

Solution to accessibility problem is to provide an environment for exchange and sharing of available data among the organizations. For this purpose, beside the necessity of activities such as policy making, culture cultivating, eliminating the institutional obstacles and ... (which are not the concern of the present essay) providing suitable tools and environment for publicizing the available data to users and providing online access of users to data as well as retrieval of the data is a fundamental solution. Therefore, this research proposes a distributed structure based on Internet GIS as suitable tool for easy access of users to the required data (Fig. 2). As shown in Fig. 2:

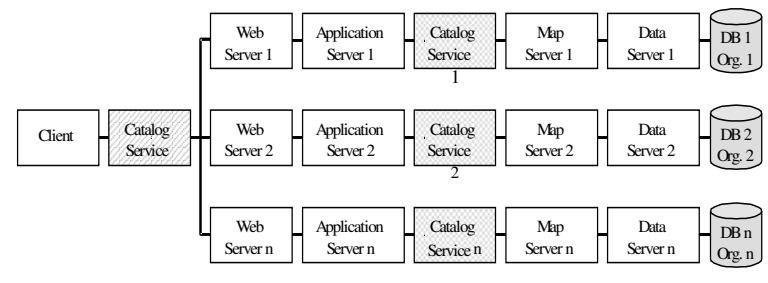

Fig. 2: General structure of a distributed architecture based on internet GIS for management and access to geomorphologic data, adopted from $^{[17]}$

- Each of the custodian organizations have produced and updated the relevant spatial data and maintained them in their databases $\left(\mathrm{DB}_{\mathrm{i}}\right.$ in Fig. 2)

- An Internet GIS service comprising five major fragments of Data Server, Map Server, Catalog Service, Application Server and Web server is created in the side of custodian organization

- This service provides the possibility of access, observation, selection and retrieval of available data in the database for the user

- The Internet GIS services are registered in a national Catalog Service. This Catalog Service contains major items of metadata dealing with the available data in the databases and the URL address of Internet GIS service relevant to each database

- The client seeking layer of special information of geomorphologic data is connected to the national Catalog Service and enters the specifications of his/her desired data

- The Catalog Service searches in the data bank of its metadata and after finding the data sought by the user, provides the user with the address of relevant websites

- By connecting to each of the Internet GIS services, the user can observe, select and collect his/her desired data

Performance of each of the segments of Internet GIS is briefly as follows:

- Web Server is a part that undertakes the main following functions: receiving the user's request, sending the request to Application Server, receiving the reply (for example, map) from the Application Server and dispatch of the reply to the client

- Application Server is an intermediary program for establishing relations between the Web Server and other programs of Internet GIS service (such as 
Map Server and Catalog Service). This unit acts as a translator between the modules

- Catalog Service contains metadata with the more details in connection with the available data in the database (In fact, a summary of this metadata exists in the national Catalog Service and with any change in any of the organizations' databases (insertion or deletion of the data or updating the data) the available metadata in the pertinent Catalog Service and the national Catalog Service is also updated). In the first step of using the Internet GIS service, the user by observing these metadata and their relation with his/her need comes to realize as to whether this service exists towards his/her desired data in the database or not. In case of availability, he/she selects the desired layers of the data and is connected to the Map Server

- Map Server is the core GIS engine of an Internet GIS. Conduction of spatial queries, selection and clipping of the available data in special geographical areas, cartographic settings of the features, etc. constitute part of the functions of this element. Output of Map Server may be dispatched to the client in the form of vector or raster (despite the data being vector on the side of the client)

- Data Server provides for spatial and attribute data required by the Map Server (in compliance with the user's request) by access to database

After finding and selecting desired data, the user can take action for electronic purchase and reception of online data or receive the data in any other form (such personal visit) by going through special stages advised by the organization taking care of the data.

Technical solution to the problems dealing with applicability is development and observance of unit standards, based on users' requirements, for geomorphologic-environmental data. These standards consist of format of the data, coordinate systems, base elliptical, definition and denomination of layers and attribute data, data type and so on. In case of correct formulation and observance of these standards, the produced data by different organizations may be combined with one another used in GIS systems.

\section{RESULTS AND DISCUSSION}

Damavand volcano conic was selected as the case study area in order to find the workability of the proposed method and architecture for management of Iran's geomorphologic-environmental data from technical viewpoints. Damavand volcano was selected as study zone because firstly, it is one of the important geomorphology phenomena of Iran. Secondly, there are not precise and clear studies of geomorphologicenvironmental features of Damavand. Thirdly, the data relating to this volcano are associated with three groups of problems pertaining to availability, accessibility and applicability despite extensive studies about this volcano. Three major stages of this case study consist of designing and standardizing the database for settlement of the problem of data applicability, collecting and storing geomorphologic-environmental data in the distributed databases for simulation of the solution of data availability and development of a distributed Internet GIS system based on proposed architecture for settlement of the problem of data accessibility as explicated later.

Designing and standardization of database: As the first step of the case study, the desired database was designed and standardized. For this purpose, firstly the conceptual model of database was designed comprising determining desired spatial data and relevant attribute data as well as the relationship of the data with one another. Then, standards of Damavand geomorphologic-environmental database were formulated. For this purpose, Geographic Markup Language (GML), (the standard format presented by the international consortium of OGC), was selected as format for storage of the data and WGS84 and UTM 39 as coordinate system and base elliptical. Spatial information layers and the relevant attribute data were defined, the type of data and manner of storing of each of them (spatial: point, line, polygon; descriptive: number, text, date and etc) specified and, generally speaking, standards of the data were drawn up. By observance of these standards, the available data in the databases could be integrated with one another and used in GIS systems. Moreover, for congruous and equal storing of the data in the Catalog Services, standard of storing the metadata was formulated.

Collecting and storing the data: For provision of data layers the following information sources and methods were used:

- The available research maps: These maps were digitally oriented in GIS environment and with a view to the formulated standard made GIS-Ready

- The available digital maps: These seamless maps were made GIS-Ready with a view to the formulated standards 
- Satellite images and aerial pictures: These data were used for production of new data layers, improvement of the available maps and updating the old ones

- Field operations: Ground inspection and control in different occasions having been accomplished for producing new data layers and bringing the available data up to date

After provision of the data layers, in order to create a distributed structure, the data were stored in separate data bases in different computers. Based on the formulated standards, the data with GLM format were stored in the SQL Server data base environment in the form of XML. Since GML is a format based on XML, its storing in the frame of a XML Database is an ideal approach for its management in a data base management system. Method of provision of each of the data layers is explained below:

Topographical map: Digital topographical maps of the State Topographical Organization at a scale of 1:25000 covered only the southern hemisphere of Damavand; therefore, in order to top off the information, the data layers of northern hemisphere of Damavand was also made digital and thus the map of the region's topography became complete. The produced data layers consist of curved lines with spaces of 10 meters, network of main rivers and subsidiary waterways, main and subsidiary roads, mountain climbing courses and dispersion of warm and cold springs, dispersion of cities and villages and scarcity of mines. Then all the data layers cited above were updated by using ASTER satellite pictures. Eventually, by integrating the data and eliminating the seamless border of sheets and the existing errors as desired by GIS and attributing the descriptive data to corresponding spatial accidents, the data became GIS-Ready.

Geological map: Enjoying a special geographical situation, Damavand lies in the confluence of two sheets of 1.250000 map of geology of Tehran and Amol and four sheets of map of 1:100000 Baladeh, Amol, Damavand and east of Tehran. As such, four maps of 1:100000 of the said digital geology were then evened out by using ASTER satellite pictures and Damavand topographical map of 1:50000 and margins of maps in the study zone were equalized. Litho logy and slope along with the relevant descriptive information were the most important data layers of these maps that were all GIDS-Ready after being updated.

Satellite pictures: In this research work, three types of satellite data were used as follows:
- ETM Satellite Picture with eight spectral band comprising seven color bands with the power of 30 meters spatial separation and one panchromatic band with the power of 15 meters spatial separation for location of thermal and magma mass as well as provision of floral coverage map were used in Iran

- ASTER Satellite Picture with 14 spectral band consisting of 3 VNIR bands with 15 meters spatial separation power, six SWIR bands with 30 meters separation power and five TI bands with 90 meters separation power for study of the region's geological structure, particularly revelation of thermal transformation also introducing the first application of ASTER pictures in survey and identification of the morphological forms of Damavand volcano were used in Iran

- SPOT Satellite Pictures with one panchromatic spectra band with 5 meters separation power and four color bands with 10 meters separation power. The information obtained from SPOT satellite fills the existing vacuum. Side-to-Side picture system provides stereo pictures that are useful for creation of numerical altitudinal model of the earth (DEM)

Climatology data: Due to lack of synoptic instruments in the zone of study, the required Fig. and information were extracted from climatology station in the region. By study of the length of statistical period in the selected station, outstanding period of studies of rainfall and heat (1980-2005 year) were selected for 25 years ${ }^{[19]}$. Then, for provision of isothermal and isorainfall maps the grading of heat compared to height was used and the cited maps were provided.

Digital elevation model: DEM is a three dimensional understanding of the earth that is produced with a view to the altitudinal situation of the region in software environment. This is a real digital image each of whose pixels have three features of geographical length and width and height from at the sea level. These pixels lie beside each other in away that provide the viewer with a three dimensional understanding. The map of Damavand DEM were made by using the curve of digital levels with 10 meter spaces in ArcGIS environment and the size of each pixel in the said map has been chosen to be 25 meters.

Map of slope: Map of slope of the Damavand conic was provided by using DEM map with dimensions of 25 meter pixels in six classes. The distances of the gradient levels were 15 degrees and the inclines given to the region were divided from zero to 89 degrees with distances of $30 \mathrm{~m}$. 
Map for direct of slope: The map for incline of slope was provided by using DEM map in ArcGIS environment. For setting up classes of the map the gradient of the slope was provided by using the approach of 9 sides of north, north-east, north, southnorth, south, south-west, west, north-west and flat regions.

Hypsometric map: For study of the erosion levels, classes of vegetation, mass and loose movements, morphological and glacial forms, etc., the region's altitudinal classification with distinct intervals were needed . As such, the hypsometric map of Damavand was provided from the altitude of 5619 up to 1450 meters at the crevice of Haraz valley by dividing to nine altitudinal classes with altitudinal distances of 500 meters.

Map of drainage basins: Almost no precise and exhaustive studies are available about location and division of drainage basins of Damavand Volcano in all slopes due to special geographical conditions, arduous access and shortage of information. As such, the present research work attempts to spot the drainage basins of the region in northern, southern, eastern and western slope. To provide the said map, primarily border of basins and then sub-basins were separated based on highest summit line and the line of water division by using topography map (curve of scales and hydrological network). Five drainage basins along with the subbasins were identified, drawn and finally GIS-Ready.

Map of iso-rain: For provision of this map, the statistics of precipitation of Climatology Station in a statistical period of 25 years was used. The average annual rainfall and altitude from the sea level in the station during the statistical period was extracted and through linear regression, relation between the height and rate of rainfall $(\mathrm{p}=0.287 \mathrm{z}-86.88)$ was obtained. Then, the above relation was applied in DEM map in ArcGIS environment and the annual average rainfall at any altitudinal level computed and classified.

Map of vegetation: The sole available map of Vegetation provided by research center of Agriculture Jihad has a scale of 1:250000 in which Damavand is not covered. Perforce, the map of floral coverage with precision of 1:50000 were provided by using ETM satellite pictures. This map located and portrayed three types of Vegetation for Damavand under the title of agricultural lands and those pertaining to garden, sporadic Vegetation and areas lacking Vegetation.
Map of glacial and sub glacial forms: At present, no suitable map that can be used as source for exact study of Damavand glaciers exist. Despite its great height and enormous snowfall, Damavand being volcanic conic does not have noticeable glaciers compared to other glacial regions of Iran. Among the active glaciers and important snowdrifts around the peak, one can refer to active glaciers of Sioleh, Dubai Sel, Esple, Khortab and Yakhar as well as snowdrifts of Kafar Darreh, Sardaq glacier. The line of snow in the glacial region in the height of 5100 meter in south slope and 4500 meter in North Slope is with slope of 26 percent to 40 percent gradient. Area of the glaciers and snowdrift and adjacent areas of glaciers surrounding the peak of Damavand have been computed to be approximately 20 square kilometers. For provision of the map of the situation of glaciers and snowdrifts of the region satellite pictures (ETM) and ground visit of the map of glacial arenas and adjacent glacial areas were provided out of the existing documents.

Slope movement: Landslide is one of the most important factors of erosion in Damavand. On account of volcanic structure of Damavand, morphology of the lavas current has a great similarity to morphology of landslide. Therefore, identification of landslide regions is not possible simply by aerial pictures. Therefore, by using ASTER satellite pictures combined with spot with the separation power of five meters as well as field operations and ground visit, over 37 slide areas were identified. The purpose behind provision of drifting regions is to make a model and provide maps of slope movement arenas for environmental management of the region.

Creation of a distributed internet GIS based on the proposed architecture: Based on the proposed architecture for geomorphologic data and environments management of Damavand, a prototype system was implemented. For creation of this system all segments of the architecture were provided and their relations with each other established.

The collected data were stored in four databases on four different computers and the developed system was installed on four computers. Also, a computer for sample installation of National Catalog Service and one computer as client were allocated.

The collected data were stored in four databases on four different computers and the developed system was installed on four computers. Also, a computer for sample installation of National Catalog Service and one computer as client were allocated. 


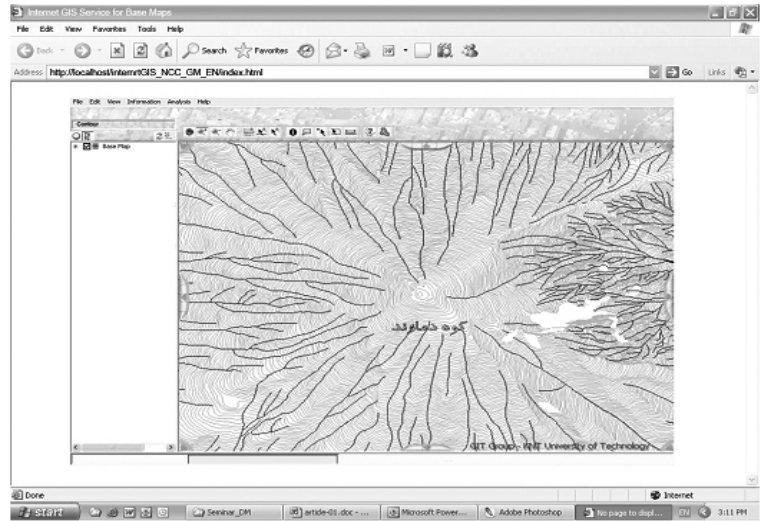

Fig. 3: User interface of the developed Internet GIS environment for observation of geomorphologic data

For creation of this system, different technologies, tools and subsidiary means such as AJAX, HTML IIS, Java Script, VB.Net, ASP.Net, XML and SQL Server were used.

Relation of these parts with each other was such that in Internet user enters the address of national Catalog Service (sample implemented) web site for searching his/her desired data and visits its website. After selection of the search method, search parameters such as the desired geographical restrictions, information layer and etc. are entered by the relevant user interface. By searching in its data, the Catalog Service introduces the address of services that may contain the desired data of the user. By connecting to each of the services, using internet GIS, user can search, observe, select and download his/her desired data. The retrieved data that re in GML format can be converted into any desired format for use in GIS of the user. Figure 3 shows the user interface of developed Internet GIS.

Having such distributed architecture, producers of geomorphologic data can transmit information regarding available data by registration of metadata in the Catalog Services. Also, by existence of a national Catalog Service, users can become aware of the available data by connecting to it, observing them online, selecting them and readily gaining access to them. Observance of standards of the unit in distributed management of these data facilitates their forthcoming combination and use by users. As such, problems related to availability, accessibility and applicability of geomorphologic data for environmental management will be settled technically.

Besides the technical solutions that employed and presented in this research, in order to make such a system operational in practice, it is necessary to pay attention to different non-technical factors to gain the support of executive organizations as the main data custodians. Clarifying the ownership of spatial data, providing required financial resources for creating and maintenance of the system, skill formation in executive organization to prepare and disseminate spatial data based on developed standards, define and establishment of accessing levels, satisfying security constrains, etc. are some examples of the non-technical factors that should be considered and satisfied by proper policymaking.

\section{CONCLUSION}

In this research, problems dealing with geomorphologic data and environmental management were elaborated. Then, an executive solution along with a distributed architecture for management of these data was presented. The proposed system and architecture were designed and presented based on standards and technologies of OGC and Internet GIS. For architectural testing and evaluation of the proposed solution, a case study for Damavand volcanic conic was conducted. In this case study, 13 sets of spatial data consisting of topography, geology, satellite picture, climatology, digital elevation model, slope, direction of the slope, hypsometry, drainage basin, iso-rainfall, vegetation, glacial arenas and sliding regions along with relevant attribute data were produced, collected and updated. Also, standard of data storage was drawn up and all available data were stored in different databases based on this standard. Moreover, a distributed system based on Internet GIS was implemented based on the conducted design. The desired system was tested. The results of the test indicated that the proposed method for data collection, updating and storage in a distributed internet-based systems can serve as a solution to settlement of problems dealing with geomorphologicenvironmental data management of Iran and other countries from technical point of view. It was also highlighted that in order to make the system operational, considering various non-technical factors to gain the support of the executive organizations is essential.

\section{ACKNOWLEDGMENT}

This article is provided via the 7022/01/03 number grant by protection of respectable search assistant of university of Tehran, respectable search assistant of university of Technology khajenasireddin Toosi, Geological survey of Iran and PHD proposal that titled Recognize Geomorphologic landforms of Damavand 
volcanic mountain and its environmental abilities with using RS and GIS by Mojgan Zareinejad under supervision of Dr. Moghimi, E, carrying on the Scientifics and Researches branch of Azad University. Thanks and appreciate them

\section{REFERENCES}

1. Ahmadi, H., 1995. Applied Geomorphology, Vol. 1, Tehran University Publishers. pp: 35-57.

2. Cook, R.U. and J.C. Doornkamp, 1998. Geomorphology in Environment Management, V. 1, translated by Shapur Gudarzinejad, SAMT Publishers, pp: 9-17.

3. Dunfey R.I., B.M. Gittings and J.K. Batcheller, 2006. Towards an open architecture for vector GIS, J. Comput. Geosci., 32 (10): 1720-1732.

4. European Union, 2007. Establishing an Infrastructure for Spatial Information in the European Community (INSPIRE), Directive 2007/2/EC of the European Parliament and of the Council of 14 March 2007, Official Journal of the European Union, L 108, 25.4.2007, http://www.ecgis.org/inspire/, visited on October 2007.

5. Feeney, M.E.F., 2003 SDIs and decision support, in developing Spatial Data Infrastructure: From Concept to Reality, Williamson, I.P., A. Rajabifard and M.E.F. Feeney, (Eds.). London and New York: Taylor and Francis, pp: 313, pp: 195-210.

6. GSI, 2004. Development of an SDI strategic plan and Conceptual Model for Geological Survey of Iran, A technical report, Geological Survey of Iran, Tehran, Iran, pp: 194.

7. INSPIRE, 2003. Report on the feedback of the Internet consultation on a forthcoming $\mathrm{EU}$ initiative establishing a framework for the creation of an Infrastructure for Spatial Information in Europe, 28 August 2003, http://inspire.jrc.it/reports/analysis_consultation_01 092003.pdf - visited on January 2004.

8. Masser, I., 2005. The Future of Spatial Data Infrastructures, ISPRS Workshop on Service and Application of Spatial Data Infrastructure, Hangzhou, China, 36 (4/W6), Oct.14-16.

9. Masser, I., A. Rajabifard and I. Williamson, 2007. Spatially enabling governments through SDI implementation. Int. J. Geo. Inform. Sci., 1-16.
10. Mansourian, A., A. Rajabifard, Valadan M.J. Zoje and I. Williamson, 2006. Using SDI and web-based systems to facilitate disaster management, J. Comput. Geosciences, 32 (6): 303-315.

11. Mansourian, A. and M.J. Valadan, 2006. Expanding SDI hierarchy for countries with nonfederated system., AsiaGIS 2006 conference, Malaysia.

12. Mansourian, A., M. Zareinejad and E. Moghimi, 2007. Creation of Geomorphologic-Environmental data of Damavand under WebGIS, (In press), Geological survey, in Scientific Research magazine of Sciences of Earth, Iran.

13. Motamed, A. and E. Moghimi, 1999. Application of Geomorphology in Planning. Tehran, SAMT Publishers, pp: 3-11.

14. Moghimi, E., 2006. Urban Geomorphology, Tehran University Publishers, pp: 2-50.

15. Moghimi, E., 2007. Necessary Geomorphologic information for Roads safety, with Emphasize soleghan Road in west of Tehran, Iran. Am. J. Environ. Sci. 3 (4): 199-204 USA.

16. MPO 2005. National Development Plan Documents, the Fourth Economic, Social and Cultural Development Plan of the Islamic Republic of Iran 2005-2009, National Special Development Plan Document (Trans-Sector), Pertaining to SubArticle 155-C of the Law of the Fourth Development Plan, 2: 41-67.

17. Peng Z.R. and M.H. Tsou, 2003. Internet GIS: Distributed Geographic Information Services for the Internet and Wireless Networks, Wiley: John Wiley and Sons, Inc. pp: 679.

18. Rajabifard, A., M.E.F. Feeney and I.P. Williamson 2003. Spatial Data Infrastructure: Concept, Nature and SDI Hierarchy, in Developing Spatial Data Infrastructure: From Concept to Reality, Williamson, I.P., A. Rajabifard and M.E.F. Feeney, (Eds.). London and New York: Taylor and Francis, pp: 313, pp: 17-42.

19. State Meteorological Organization, Statistics and Information of Climatology Rineh Station of 25 year old period (1980 to 2005), www.weather.ir

20. Williamson, I.P., A. Rajabifard and M.E.F. Feeney, 2003. Developing Spatial Data Infrastructure: From Concept to Reality, London and New York: Taylor and Francis, pp: 313. 